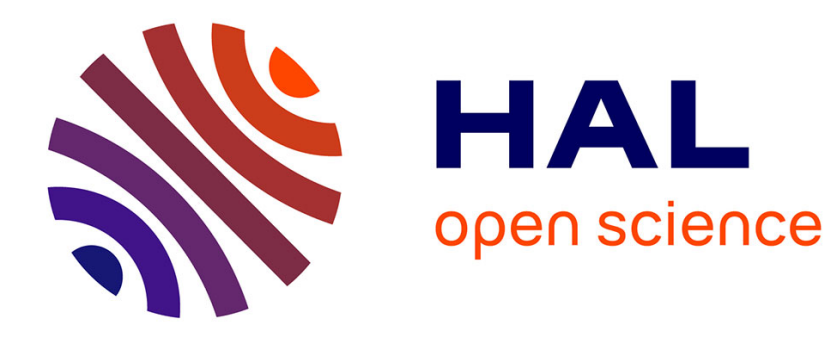

\title{
Logic, Fast and Slow: Advances in Dual-Process Theorizing
}

Wim de Neys, Gordon Pennycook

\section{To cite this version:}

Wim de Neys, Gordon Pennycook. Logic, Fast and Slow: Advances in Dual-Process Theorizing. Current Directions in Psychological Science, 2019, 28 (5), pp.503-509. 10.1177/0963721419855658 . hal-02438850

\section{HAL Id: hal-02438850 https://hal.science/hal-02438850}

Submitted on 14 Jan 2020

HAL is a multi-disciplinary open access archive for the deposit and dissemination of scientific research documents, whether they are published or not. The documents may come from teaching and research institutions in France or abroad, or from public or private research centers.
L'archive ouverte pluridisciplinaire HAL, est destinée au dépôt et à la diffusion de documents scientifiques de niveau recherche, publiés ou non, émanant des établissements d'enseignement et de recherche français ou étrangers, des laboratoires publics ou privés. 


\section{LOGIC, FAST AND SLOW: ADVANCES IN DUAL-PROCESS THEORIZING}

Wim De Neys (LaPsyDE, CNRS \& Paris Descartes University, France)

Gordon Pennycook (Hill/Levene Schools of Business, University of Regina, Canada)

(In press) - Current Directions in Psychological Science

Word count: 2811

Corresponding author:

Wim De Neys

LaPsyDE (UMR CNRS 8240)

Sorbonne - Labo Binet

Paris Descartes University

46 Rue Saint-Jacques

75005 Paris

France

Email: wim.de-neys@parisdescartes.fr 


\begin{abstract}
Studies on human reasoning have long established that intuitions can bias inference and lead to violations of logical norms. Popular dual-process models, which characterize thinking as an interaction between intuitive ("System 1") and deliberate ("System 2") thought processes, have presented an appealing explanation for this observation. According to this account, logical reasoning is traditionally considered as a prototypical example of a task that requires effortful deliberate thinking. In recent years, however, a number of findings obtained with new experimental paradigms have questioned the traditional dual-process characterization. A key observation is that people can process logical principles in classic reasoning tasks intuitively and without deliberation. We review the paradigms and sketch how this work is leading to the development of revised dual-process models.
\end{abstract}

Keywords: Dual-Process Theory; Reasoning; Decision-Making; Bias 


\section{INTRODUCTION: BIAS AND DUAL-PROCESS MODELS 1.0}

Sometimes a solution to a problem pops in to mind instantly and effortlessly whereas at other times arriving at a decision takes time and effort. This simple dichotomy between a more intuitive ("System 1") and more deliberate ("System 2") type of thinking lies at the heart of the dual-process theories that have been prominent in the reasoning and decision-making field since the 1970s. More recently, dual-process theory has gained a broader popularity, having been featured in best-selling books (e.g., Kahneman, 2011) and applied to a wide range of fields (Evans, 2008)-from moral philosophy (Greene, 2015) to prosocial cooperation (Rand, Greene, \& Nowak, 2012).

The rise and development of dual-process theory in research on human thinking can be linked to an attempt to explain the phenomenon of "bias" in reasoning and decision-making research (Evans, 2016; Kahneman, 2011). Decades of research have shown that people readily violate the most elementary logical, mathematical, or probabilistic rules when a task cues an intuitive response that conflicts with these principles (see Table 1 for illustrations). Hence, reasoners often appear to be biased by their intuitions. The broad dual-process framework represents a simple and elegant explanation for the tendency for humans to be biased: Logical and probabilistic principles, unlike simple intuitive tasks like making stereotypical judgments or executing stimulus-response pairings, require demanding deliberate processing (e.g., Evans, 2008; Stanovich \& West, 2000). Because human reasoners have a strong tendency to minimize demanding computations, they will often refrain from engaging or completing the slow deliberate processing when mere intuitive processing has already cued a response (Evans \& Stanovich, 2013; Kahneman, 2011). Consequently, most reasoners will simply stick to the intuitive response that quickly came to mind and fail to consider the logical implications. Hence, people will typically be biased because they do not detect that their intuitive hunch conflicts with logical considerations. The few reasoners who manage to give the logical response will be those who have sufficient motivation and resources to complete the deliberate computations and override the initially generated intuitive response (Stanovich \& West, 2000). 


\section{INTUITIVE LOGIC}

The idea that logical reasoning requires deliberate processing fits nicely with the common belief that following logical or mathematical rules is hard (Kahneman, 2011). However, in the last decade numerous findings have questioned this key assumption and indicate that people have intuitive access to logical principles in classic reasoning tasks. That is, logic does not necessarily require System 2 . Here we review the experimental paradigms that led to this discovery.

\section{Conflict Detection Paradigm}

The conflict detection paradigm was developed to test whether reasoners who are "biased" - that is, they opt for an intuitively cued response instead of the logical responsedetect that their answer violates logical considerations (De Neys \& Glumicic, 2008). Put differently, the question is whether biased reasoners show some sensitivity to their errors. To assess this, the conflict detection paradigm presents participants with standard "conflict" versions of classic reasoning problems and newly constructed "no-conflict" control versions (as illustrated in Table 1). In the classic conflict versions, an intuitive association cues a response that conflicts with the logical response. In the no-conflict versions, this conflict is removed and both the intuitive association and logical considerations point to the same conclusion. Bias and conflict sensitivity are then reflected in differences in how people process both versions. If biased reasoners do not take logical principles into account, then conflict should be irrelevant and have no impact on reasoning.

Results indicate that biased reasoners often do show conflict sensitivity. For example, biased reasoners display increased response doubt-as reflected in lower confidence and longer decision latencies-when they give a biased answer on the conflict problems (De Neys, 2012). This conflict sensitivity is also observed under time-pressure and cognitive load (De Neys, 2017a). Since deliberate processing is often assumed to be more time and cognitive resource demanding than intuitive processing, this finding implies that conflict detection occurs without the aid of System 2. Thus, the finding that biased reasoners show logical conflict sensitivity 
when deliberate processing is experimentally sidelined suggests they are processing the logical principles intuitively.

\section{Two-Response Paradigm}

The two-response paradigm was designed to explore the time-course of intuitive and deliberate processing (Thompson, Turner, \& Pennycook, 2011). In this paradigm, participants are asked to give two consecutive responses. First, they are asked to give their initial hunch and to respond as fast as possible with the first intuitive answer that comes to mind. Afterwards, they are allowed to take all the time they want to reflect on the problem and generate a final response. To make sure that the initial response is generated intuitively, it has to be generated under time-pressure and/or cognitive load (Bago \& De Neys, 2017; Newman et al., 2017). This procedure again helps to minimize possible deliberation. The critical finding is that many reasoners who give a logic final response (i.e., after deliberation was allowed) already gave this response in the initial response stage in which they had to reason intuitively (Bago \& De Neys, 2017, 2019a). Hence, logical responders do not necessarily need to deliberate to override a faulty intuition; often their intuitive response is already logical. This further indicates that logical principles can be processed intuitively in common reasoning tasks.

\section{Instructional Set Paradigm}

In traditional reasoning studies, participants are expected to reason in accordance with logical principles. Typically they are explicitly told to disregard their intuitive beliefs. In the instructional set paradigm, these instructions are reversed (Handley, Newstead, \& Trippas, 2011). People are not asked to indicate which response is logically or probabilistically correct. Rather, they are asked to follow their intuition and indicate whether or not the conclusion is believable. The key observation is that people are slower to answer (and less confident) in those cases in which the intuitively cued belief-based response conflicts with logicality (Pennycook, Trippas, Handley, \& Thompson, 2014; Trippas, Thompson, \& Handley, 2017). These effects are present even if deliberation is minimized by forcing participants to respond as quickly as possible (Thompson, Trippas, Evans, \& Pennycook, 2018). Hence, although people are 
not instructed to reason logically, they spontaneously seem to do so and this interferes with their ability to make belief-based judgments.

\section{Logic-Liking Paradigm}

In the logic-liking paradigm (Morsanyi \& Handley, 2011) participants are presented with classic reasoning problems but are not asked to solve them. They are simply asked to make seemingly trivial judgments such as how much they 'like' the conclusion or even how bright they perceive it to be. The task and instructions explicitly avoid any reference to logic, reasoning or validity. People are told they will see a number of statements and will simply have to indicate how much they like them or how bright they look on the screen. Quite strikingly, results show that people implicitly discriminate valid and invalid conclusions in this task. Although people are not instructed to reason, they nevertheless indicate that they like valid conclusions more than invalid ones and judge them to be brighter (Trippas, Handley, Verde, \& Morsanyi, 2017).

Why do people judge a valid conclusion as more likable or brighter when they are not even expected to reason? The explanation is built on a fluency misattribution account (Reber, Winkielman, \& Schwarz, 1998): Specifically, more fluently processed information is known to give rise to positive affect. If logical validity is processed intuitively, more fluently processed

valid conclusions can be expected to give rise to positive feelings (Morsanyi \& Handley, 2011). The idea is that this affective fluency signal is subsequently being interpreted as an increase in likability or brightness.

Irrespective of the specific fluency account, just like the instructional set findings, the liking paradigm indicates that people seem to spontaneously take logical validity into account. This further suggests that they can process elementary logical features intuitively without engaging in a deliberate reasoning process.

\section{TOWARDS A DUAL-PROCESS MODEL 2.0}


The intuitive logic findings are hard to account for in the traditional dual-process model. Various scholars have therefore claimed it is time to move to a revised dual-process model (Ball, Thompson, \& Stupple, 2017; Banks \& Hope, 2014; De Neys, 2012; Handley et al., 2011; Pennycook, Fugelsang, \& Koehler, 2015; Reyna, Rahimi-Golkhandan, Garavito, \& Helm, 2017; Thompson et al., 2018). One central aspect of this emerging perspective is that our conception of intuitive ("System 1") processing needs to be upgraded (De Neys, 2017b). Computations that were traditionally considered to require deliberate processing can also be cued intuitively. Under this view, multiple types of intuitive responses will be cued simultaneously (De Neys, 2012; Pennycook et al., 2015). For example, when we're faced with a classic reasoning problem one of these will be the traditional "heuristic" intuitive response that is based on prior beliefs and other associations. But a critical second response will be what we can refer to as a "logical" intuitive response which is based on elementary knowledge of basic logical and probabilistic principles.

Crucially, different intuitions can vary in their strength or activation level (Bago \& De Neys, 2017; Pennycook et al., 2015; Thompson et al., 2018). In cases where multiple conflicting intuitive responses are cued, the strength difference will determine whether conflict is registered (the more similar the strength, the higher the likelihood of conflict detection) and whether deliberate processing will be called upon (Pennycook et al., 2015). This deliberate processing can then be used to override the dominant intuitive response or to simply rationalize it and look for an explicit justification that supports it (Pennycook et al., 2015).

Figure 1 sketches three illustrative cases. Obviously, the postulation of logical intuitions does not entail that people will always respond logically or that logical responding cannot be deliberate. Rather, the idea is that people have different types of intuitions-some of which are logical (accurate)-and that these intuitions can differ in strength. In some cases, the logical intuition will dominate the competing heuristic intuition (Figure 1B). Here one can respond in accordance with logic without further deliberation. In other cases, the heuristic intuition will dominate (Figure $1 \mathrm{~A}$ and $1 \mathrm{C}$ ), and logical responding will therefore require deliberation. Crucially, the presence of a competing logical intuition allows people to detect conflict, which then can trigger the deliberative override of the heuristic intuition and result in a classic, "slow" 
logical response. If the override fails, the reasoner will give the heuristic response. Any deliberate processing will be primarily used here to find an explicit justification for the dominant heuristic intuition (i.e., rationalization). Thus, even with successful conflict detection and resulting deliberation, people may still end up giving a "biased" answer.

Whether or not deliberate override will occur is tied to the likelihood of conflict detection. The more similar the strength of the competing intuitions (Figure 1C), the more conflict will be experienced, and the more likely that deliberation will occur. This, in turn, increases the likelihood that the dominant intuition will be overridden. Results from the tworesponse and conflict detection paradigm indeed indicate that participants who show a more pronounced conflict detection effect (e.g., as reflected in increased doubt about their initial response) are more likely to change their initial heuristic response after deliberation relative to those who are less responsive to conflict (Bago \& De Neys, 2017; Thompson et al., 2011). Experimental manipulations that are aimed to increase or decrease the strength of logical intuitions (e.g., by making probabilities in base-rate neglect problems such as in Table 1 more or less extreme) further support this assumption (Bago \& De Neys, 2019a; Pennycook et al., 2015).

A key implication of the logical intuition findings and dual-process evolutions is that we need to re-think the traditional view on the nature of biased and logical responding. Biased responding does not necessarily result from a failure to recognize conflict. Although reasoners might not always manage to override their heuristic intuition, they are not necessarily oblivious to its questionable status. At the other end of the spectrum, sound reasoning does not necessarily require a deliberation process. Although deliberate override of an initial dominant heuristic intuition sometimes occurs, the most prolific reasoners do not always need it. This implies that good reasoners do not necessarily deliberate better; often they will simply have better intuitions (Bago \& De Neys, 2019b; Thompson et al., 2018).

\section{OUTSTANDING ISSUES}

\section{Boundary conditions and individual differences}


The dual-process view " 2.0 " that is emerging is a work-in-progress. There remain important challenges. For example, the framework does not entail that we have logical intuitions for every possible problem we face in life. Rather, the claims concern the type of elementary principles that are evoked in classic reasoning problems (De Neys, 2012). The idea is that most adult reasoners managed to automatize these principles because they have been extensively exposed to them (e.g., in the school curriculum). Moreover, how complex these principles can be is an active open area of research (Trippas et al., 2016). Studies also point to individual differences: Although the modal biased reasoner might show conflict detection, a subgroup of individuals does not (Frey, Johnson, \& De Neys, 2018; Pennycook et al., 2015). It is possible that this group has not managed to automatize the application of the necessary logical knowledge (Stanovich, 2018). Pinpointing the exact boundary conditions and individual differences remains an important challenge in the coming years.

\section{Origin logical intuition}

The concept of a logical intuition does not imply that it is inborn or instinctive. Although infants might show some early logical sensitivity (Cesana-Arlotti et al., 2018), it is assumed that people's intuitive logical knowledge emerges from a learning process in which key principles have been practiced to automaticity (De Neys, 2012). The basic mechanism of a deliberate-tointuitive automatization process (e.g., Shiffrin \& Schneider, 1977) has long been recognized in traditional dual-process models. For example, it is long been assumed that experts in various fields are characterized by the automatization of previously deliberate procedures (Kahneman, 2011). Hence, the underlying automatization process that is assumed to give rise to logical intuitions is not new. The key insight is that it applies to a much wider range of phenomena-

including mastery of basic logical principles by laypeople-than previously believed. Nevertheless, the logical automatization assumption remains to be tested directly.

\section{Role of deliberation?}

The case for fast logical intuitions might seem to downplay the role of "System 2" deliberation in dual-process theory. If we can generate logical responses intuitively, why do we 
even need to engage in effortful deliberation? The answer brings us back to the idea that different types of intuitions will be cued simultaneously. The generation of a logical intuition does not imply that it will dominate. Logical responding to the task will still require a deliberate override when the competing heuristic intuition is stronger. Furthermore, even when people have dominant logical intuitions, the fact that deliberation is not needed to override does not imply it cannot serve a different function. For example, Bago and De Neys (2019b) observed that after deliberation (in a two-response study) people had little trouble properly justifying their logical responses. Such correct justifications were much less likely for logical responses in the initial response stage. Hence, just like reasoners may use deliberation to look for a justification to support a heuristic intuition, they may need it to come up with a proper, explicit justification for their intuitive logical insight. In theory, such a process can play an important role in communication (e.g., Mercier \& Sperber, 2017), but its precise nature remains to be clarified.

\section{Generalization}

We noted that the core ideas that were put forward by the original dual-process model have been applied in various fields. This led to dual-process models of, for example, prosocial cooperation (Rand et al., 2012) and moral reasoning (Greene, 2015) that became highly influential in their own right. The research reviewed here indicates that there are good reasons to question core assumptions of the traditional dual-process architecture that inspired these models. In theory, the various paradigms we introduced can be used to test dual-process assumptions beyond logical reasoning tasks. Interestingly, initial findings with the conflict detection and two-response paradigm point to a remarkable similarity between logical and moral reasoning: The moral response that is traditionally believed to result from deliberate processing (i.e., calculating the greater good) often is cued intuitively (e.g., Bago \& De Neys, 2019c; Bialek \& De Neys, 2017). Although this lends some credence to the generality of the findings it will be critical to test the applicability of the new architecture in various contexts.

\section{CONCLUSION}


Research with new experimental paradigms indicates that logical processing can be done intuitively. We sketched how this is leading to a revision of popular dual-process model assumptions. Although the traditional dual-process model has been highly instrumental, we believe it is time to move to a new conceptualization. We hope that the many students and scholars who are interested in the dual-process perspective will take note of the new developments and integrate them in their work.

\section{RECOMMENDED READING}

Kahneman, D. (2011). Thinking, Fast and Slow. New York, NY: Farrar, Straus and Giroux. Accessible overview of bias research and the traditional dual-process model account.

Evans, J. St. B., \& Stanovich, K. E. (2013). Dual-process theories of higher cognition advancing the debate. Perspectives on Psychological Science, 8, 223-241.

A detailed overview of the traditional dual-process model, common misconceptions, and critiques.

Pennycook, G., Fugelsang, J. A., \& Koehler, D. J. (2015). What makes us think? A three-stage dual-process model of analytic engagement. Cognitive Psychology, 80, 34-72.

Prototypical example of a dual-process model 2.0.

De Neys, W. (Ed.) (2017b). Dual Process Theory 2.0. Oxon, UK: Routledge.

Edited volume that gives a detailed overview of the new experimental paradigms, evolutions, and current challenges in dual-process theorizing. 


\section{ACKNOWLEGMENTS}

We would like to acknowledge support of the Agence Nationale de la Recherche (ANR-16-CE280010-01). 


\section{REFERENCES}

Bago, B., \& De Neys, W. (2017). Fast logic?: Examining the time course assumption of dual process theory. Cognition, 158, 90-109.

Bago, B., \& De Neys, W. (2019a). The smart System 1: Evidence for the intuitive nature of correct responding on the bat-and-ball problem. Thinking \& Reasoning. Advance online publication. doi: 10.1080/13546783.2018.1507949.

Bago, B., \& De Neys, W. (2019b). Advancing the specification of dual process models of higher cognition: a critical test of the hybrid model view. Thinking \& Reasoning. Advance online publication. doi.org/10.1080/13546783.2018.1552194

Bago, B., \& De Neys, W. (2019c). The intuitive greater good: Testing the corrective dual process model of moral cognition. Journal of Experimental Psychology: General. Advance online publication. doi: 10.1037/xge0000533

Ball, L., Thompson, V., \& Stupple, E. (2017). Conflict and dual process theory: the case of belief bias. In W. De Neys (Ed.), Dual Process Theory 2.0. Oxon, UK: Routledge.

Banks, A. P., \& Hope, C. (2014). Heuristic and analytic processes in reasoning: An event-related potential study of belief bias. Psychophysiology, 51, 290-297.

Białek, M., \& De Neys, W. (2017). Dual processes and moral conflict: Evidence for deontological reasoners' intuitive utilitarian sensitivity. Judgment and Decision Making, 12, 148-167.

Cesana-Arlotti, N., Martín, A., Téglás, E., Vorobyova, L., Cetnarski, R., \& Bonatti, L. L. (2018). Precursors of logical reasoning in preverbal human infants. Science, 359(6381), 12631266.

De Neys, W. (2012). Bias and conflict a case for logical intuitions. Perspectives on Psychological Science, 7, 28-38.

De Neys, W. (2017a). Bias, conflict, and fast logic: Towards a hybrid dual process future? In W. De Neys (Ed.), Dual Process Theory 2.0. Oxon, UK: Routledge.

De Neys, W. (Ed.) (2017b). Dual Process Theory 2.0. Oxon, UK: Routledge.

De Neys, W., \& Glumicic, T. (2008). Conflict monitoring in dual process theories of thinking. Cognition, 106, 1248-1299. 
Evans, J. St. B. (2008). Dual-processing accounts of reasoning, judgment, and social cognition. Annual Review of Psycholgy, 59, 255-278.

Evans, J. St. B. (2016). Reasoning, biases and dual processes: The lasting impact of Wason (1960). The Quarterly Journal of Experimental Psychology, 69, 2076-2092.

Evans, J. St. B., \& Stanovich, K. E. (2013). Dual-process theories of higher cognition advancing the debate. Perspectives on Psychological Science, 8, 223-241.

Frey, D., Johnson, E. D., \& De Neys, W. (2018). Individual differences in conflict detection during reasoning. Quarterly Journal of Experimental Psychology, 71, 1188-1208.

Greene, J.D. (2015) The rise of moral cognition. Cognition, 135, 39-42.

Handley, S. J., Newstead, S. E., \& Trippas, D. (2011). Logic, beliefs, and instruction: A test of the default interventionist account of belief bias. Journal of Experimental Psychology: Learning, Memory, and Cognition, 37, 28-43.

Kahneman, D. (2011). Thinking, Fast and Slow. New York, NY: Farrar, Straus and Giroux.

Mercier, H., \& Sperber, D. (2017). The enigma of reason. Harvard University Press.

Morsanyi, K., \& Handley, S. J. (2012b). Logic feels so good-I like it! Evidence for intuitive detection of logicality in syllogistic reasoning. Journal of Experimental Psychology: Learning, Memory, and Cognition, 38, 596.

Newman, I., Gibb, M., \& Thompson, V. A. (2017). Rule-based reasoning is fast and belief-based reasoning can be slow: Challenging current explanations of belief -bias and base-rate neglect. Journal of Experimental Psychology: Learning, Memory, and Cognition, 43, 1154-1170.

Pennycook, G., Fugelsang, J. A., \& Koehler, D. J. (2015). What makes us think? A three-stage dual-process model of analytic engagement. Cognitive Psychology, 80, 34-72.

Pennycook, G., Trippas, D., Handley, S. J., \& Thompson, V. A. (2014). Base rates: Both neglected and intuitive. Journal of Experimental Psychology: Learning, Memory, and Cognition, 40, 544-554.

Rand, D. G., Greene, J. D., \& Nowak, M. A. (2012). Spontaneous Giving and Calculated Greed Nature, 489, 427-430. 
Reber, R., Winkielman, P., \& Schwarz, N. (1998). Effects of perceptual fluency on affective judgments. Psychological science, 9, 45-48.

Reyna, V. F., Garavito, D. M., Rahimi-Golkhandan, S., \& Helm, R. K. (2017). The fuzzy-trace dual process model. In W. De Neys (Ed.), Dual Process Theory 2.0 (pp. 90-107). Oxon, UK: Routledge.

Shiffrin, R. M., \& Schneider, W. (1977). Controlled and automatic human information processing: II. Perceptual learning, automatic attending and a general theory. Psychological Review, 84, 127-190.

Stanovich, K. E. (2018). Miserliness in human cognition: the interaction of detection, override and mindware. Thinking \& Reasoning, 24, 423-444.

Stanovich, K. E., \& West, R. F. (2000). Individual differences in reasoning: Implications for the rationality debate. Behavioral and Brain Sciences, 23, 645-665.

Thompson, V. A., Pennycook, G., Trippas, D., \& Evans, J. S. B. (2018). Do smart people have better intuitions?. Journal of Experimental Psychology: General, 147, 945.

Thompson, V. A., Turner, J. A. P., \& Pennycook, G. (2011). Intuition, reason, and metacognition. Cognitive Psychology, 63, 107-140.

Trippas, D., Handley, S. J., Verde, M. F., \& Morsanyi, K. (2017). Logic Brightens My Day: Evidence for Implicit Sensitivity to Logical Validity. Journal of Experimental Psychology: Learning, Memory, and Cognition, 42, 1448-1157.

Trippas, D., Thompson, V. A., \& Handley, S. J. (2017). When fast logic meets slow belief: Evidence for a parallel-processing model of belief bias. Memory \& cognition, 45, 539552. 
Table 1. Illustration of classic reasoning problems. Both standard (a.) and control (b.) versions are shown. The standard versions cue an intuitive response that conflicts with the logical response (i.e., the response consistent with standard logic or probability theory principles, highlighted in bold). In the control versions the cued intuitive response is consistent with the logical response.

\begin{tabular}{|c|c|c|c|}
\hline Syllogistic $r$ & ing problem: & & \\
\hline a. Standard & flict" version & b. Control " & flict" version \\
\hline Premises: & $\begin{array}{l}\text { All flowers need water } \\
\text { Roses need water }\end{array}$ & Premises: & $\begin{array}{l}\text { All flowers need water } \\
\text { Roses are flowers }\end{array}$ \\
\hline Conclusion: & Roses are flowers & Conclusion: & Roses need water \\
\hline 1. The concl & s follows logically & 1. The concl & follows logically \\
\hline 2. The conc & does not follow logically & 2. The concl & does not follow logically \\
\hline
\end{tabular}

\section{Base-rate neglect problem:}

a. Standard "Conflict" version

A psychologist wrote thumbnail descriptions of a sample of 1000 participants consisting of 995 people whose favorite drink is wine and 5 people whose favorite drink is beer. The description below was chosen at random from the 1000 available descriptions.

Ryan is 27 and lives in Virginia. He drives to work in his truck and likes to wear shirts of his favorite NFL team. He loves hanging out with his buddies.

Which one of the following two statements is most likely?

1. Ryan's favorite drink is wine

2. Ryan's favorite drink is beer

\section{b. Control "No Conflict" version}

A psychologist wrote thumbnail descriptions of a sample of 1000 participants consisting of 995 people whose favorite drink is beer and 5 people whose favorite drink is wine. The description below was chosen at random from the 1000 available descriptions.

Ryan is 27 and lives in Virginia. He drives to work in his truck and likes to wear shirts of his favorite NFL team. He loves hanging out with his buddies.

Which one of the following two statements is most likely? 1. Ryan's favorite drink is wine

2. Ryan's favorite drink is beer

Rationale: In the standard version intuitive beliefs based on the stereotypical description ("a truck driving southern NFL fan typically drinks beer") conflict with the response that is favoured by the base-rate probabilities (i.e., there are far more wine drinkers in the sample). In the control version the base-rates are switched around so that both the base-rates and description cue the same response.

\section{Bat-and-ball problem:}

\section{a. Standard "Conflict" version}

A bat and a ball together cost $\$ 1.10$.

The bat costs $\$ 1$ more than the ball.

How much does the ball cost?
(5 cents)

\section{b. Control "No Conflict" version}

A bat and a ball together cost $\$ 1.10$.

The bat costs $\$ 1$.

How much does the ball cost? (10 cents)

Rationale: Most people readily answer "10 cents" instead of the correct "5 cents" to the standard problem because they intuitively parse the \$1.10 in \$1 and 10 cents. In the control version this intuitive parsing is also mathematically correct. 


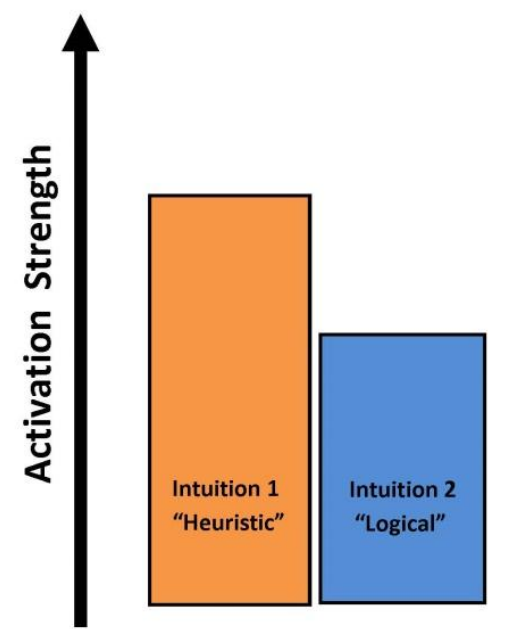

A

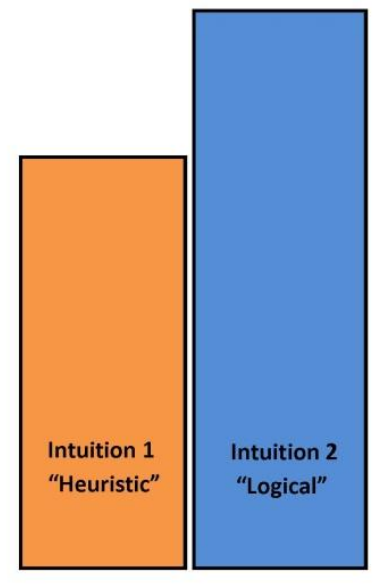

B

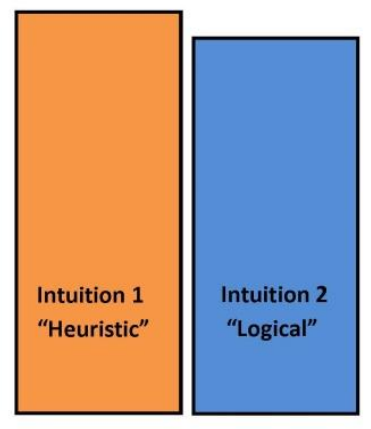

C

Figure 1. A key feature of the dual process model 2.0 view is that different types of intuitions will be generated that can differ in activation strength. Three prototypical cases are illustrated. The modal case $(A)$ is the one in which the heuristic intuition dominates. In cases the logical intuition dominates $(B)$ the logical response will be generated without further deliberation. The more similar the activation strength $(C)$, the more likely that the dominant intuition will be overridden via deliberation. 